\title{
EDITORIAL:
}

\section{Research in the Clinical Neurosciences}

This issue of the Journal includes a summary of a symposium on "Future Directions for Research in the Clinical Neurosciences" which was held in conjunction with the 16th Canadian Congress of Neurological Sciences. As with many symposia of this type, the number of questions and problems raised far exceeded the number of solutions which were proposed. Nevertheless, several important points emerged from the discussions and deserve further comment.

The phenomenonal advances in basic neuroscience knowledge over the past one to two decades raise hopes that solutions to many of the unsolved problems facing neurology and neurosurgery may be found in the not too distant future. However, the transfer of this new knowledge and technology to the bedside is not something which occurs automatically. It must be actively promoted and the responsibility falls on the clinical neuroscientist.

How can this be accomplished? How can we strengthen the interface between basic and clinical neuroscience? Perhaps the most immediate need is to increase the number of people working at this interface - the socalled physician scientist or clinical investigator. But concern was expressed during the symposium regarding the declining numbers of M.D.s entering research in all fields including the neurosciences. There has been a definite trend in both Canada and the United States for an increased proportion of research grants to be awarded to full time basic scientists rather than M.D. or M.D./PhD investigators.

A clinical trainee who wishes to develop a career in research is faced with numerous problems and conflicts of interest. Funding for research fellowships is limited and is often at a level considerably less than that for a senior clinical resident. At the completion of training the young investigator must compete with full time scientists for operating grants to support his research. If he is to remain clinically competent and continue to work with patients he must devote at least a moderate portion of his time to patient care. Often he will find himself working alongside colleagues who enjoy substantially higher incomes in full time clinical practice. In most institutions he will be seen as an "academic" and will be expected to take on a number of teaching and administrative responsibilities which must be incorporated into the already limited time available for research and patient care.

Not surprisingly, there is a high attrition rate in this field. Some individuals, having devoted considerable time to research training, leave research altogether and become full time clinicians and teachers; others opt in the other direction and become full time bench scientists. To remain competitive they may concentrate on basic problems where results are often more easily obtained than in many areas of clinical investigation. Thus the focus on clinical applications may be lost.

Too often we tend to blame all our problems and lack of progress on insufficient funding, assuming that a sudden influx of money will immediately change the situation. However, advances in the clinical neurosciences are going to require more than this. We need to create an increased awareness of the problems affecting the nervous system. Our students, colleagues, and the general public must be made aware of the urgent need for more highly focused research in the clinical neurosciences, and we must convey the attitude that there are problems which can be solved by dedicated research.

To increase the number of clinical investigators it will be necessary to expose students to research at an early stage in their careers and provide them with the opportunity to undertake supervised research projects. The development of combined M.D./PhD programs at a number of medical schools in the United States and also a few schools in Canada is a step in the right direction. Residency programs in neurology and neurosurgery should be structured to provide our most talented residents with the opportunity to gain research training, and new mechanisms must be found to support the individual who has completed clinical training and is prepared to undertake an additional one to three years of training to become a full fledged investigator.

However, the problems of clinical neuroscience are not going to be solved if we focus only on the clinician. The new ideas and technological advances are going to continue to come from the laboratory of the basic neuroscientist. It is therefore important that this individual be aware of the major unsolved problems affecting the human nervous system. The education of graduate students should include some exposure to the clinical neurosciences. A notable advance in this direction is the inauguration by the Society for Neuroscience of special courses designed to familiarize graduate students with selected problems in clinical neurology and neurosurgery.

Emphasis should be placed on the development of research teams which include both clinical and basic neuroscientists. New job opportunities need to be created to allow some basic neuroscientists to carry out their work in clinical departments. There is a need for more program type grants which will provide funding for a team of investigators carrying out "mission oriented" research on selected clinical problems.

Some of these recommendations will require that our granting agencies reexamine their policies and priorities and develop new mechanisms for funding clinically oriented research. But despite the chronic deficiencies in funding, there are reasonable grounds for optimism and it is not too unrealistic to hope that over the next 20 years we shall see advances in the clinical neurosciences which will match those which have occurred in the basic neurosciences during the past 20 years.

Robert G. Lee 
XVII CANADIAN CONGRESS OF NEUROLOGICAL SCIENCES

FOUR SEASONS HOTEL

Toronto, Ontario

June 23-26, 1982

JUNE 23, 1982 Pre-Congress Courses

1. Neuro-Ophthalmology

2. Recent Advances in Diagnosis and Treatment

3. Electromyography

4. Methodology of Clinical Research

JUNE 24, 25, 26, 1982 Plenary Sessions and

Free Communications

DEADLINE FOR SUBMISSION OF ABSTRACTS - FEBRUARY 15, 1982

FOR FURTHER INFORMATION CONTACT:

Dr. R.P. Humphreys

Room 1504

Hospital for Sick Children

555 University Avenue

Toronto, Ontario, M5G 1X8

XVII Canadian Congress of Neurological Sciences

Toronto, Ontario June 23-26, 1982 